\title{
Synthesis of Phospholipid-Protein Conjugates as New Antigens for Autoimmune Antibodies
}

Arindam Maity ${ }^{1,2}$, Claudia Macaubas ${ }^{3}$, Elizabeth Mellins ${ }^{3}$ and Kira Astakhova ${ }^{1, *}$

1 Nucleic Acid Center, Department of Physics, Chemistry and Pharmacy, University of Southern

Denmark, Campusvej 55, Odense 5230, Denmark; E-Mail: arindam.ju05@gmail.com

2

Dr. B C Roy College of Pharmacy and AHS, Durgapur, West Bengal 713212, India

3 Divisions of Human Gene Therapy and Pediatric Rheumatology, Program in Immunology, Stanford University School of Medicine, 269 Campus Drive, Stanford, MC 5164, USA;

E-Mails: macaubas@stanford.edu (C.M.); mellins@stanford.edu (E.M.)

* Author to whom correspondence should be addressed; E-Mail: ias@sdu.dk;

Tel.: +45-6550-2510.

Academic Editor: Derek J. McPhee

Received: 10 April 2015 / Accepted: 28 May 2015 / Published: 3 June 2015

\begin{abstract}
Copper(I)-catalyzed azide-alkyne cycloaddition, or CuAAC click chemistry, is an efficient method for bioconjugation aiming at chemical and biological applications. Herein, we demonstrate how the CuAAC method can provide novel phospholipid-protein conjugates with a high potential for the diagnostics and therapy of autoimmune conditions. In doing this, we, for the first time, covalently bind via 1,2,3-triazole linker biologically complementary molecules, namely phosphoethanol amine with human $\beta 2$-glycoprotein I and prothrombin. The resulting phospholipid-protein conjugates show high binding affinity and specificity for the autoimmune antibodies against autoimmune complexes. Thus, the development of this work might become a milestone in further diagnostics and therapy of autoimmune diseases that involve the production of autoantibodies against the aforementioned phospholipids and proteins, such as antiphospholipid syndrome and systemic lupus erythematosus.
\end{abstract}

Keywords: CuAAC click chemistry; antiphospholipid syndrome; antigens; $\beta 2$-glycoprotein I; phosphoethanolamine; prothrombin 


\section{Introduction}

Autoimmune diseases are very diverse and can affect almost any part of the body, including the heart, brain, nerves, muscles, skin, eyes, joints, lungs, kidneys, glands, the digestive tract, and blood vessels $[1,2]$. Among such conditions, antiphospholipid syndrome (APS) is a multi-system autoimmune disorder characterized by arterial and/or venous thrombosis or recurrent fetal loss. APS is also characterized by presence of antiphospholipid antibodies (a-PL Abs, or a-PLs) [3-6]. In clinical practice, anti-cardiolipin antibodies (a-CL), anti-phosphoethanolamine (a-PE) and the lupus anticoagulant (LA) are the most established a-PL tests for the diagnosis of APS [7] (Figure 1). APS can also occur in isolation or in association with other autoimmune diseases such as systemic lupus erythematosus [8]. The clinical utility of routinely used a-PL assays have some uncertainty due to instability and heterogeneity of currently applied antigens [9]. Phospholipids are sensitive to oxidation and unstable upon freeze storage in solution. Moreover, new a-PLs may also expand the utility of the assay. This is especially important for diagnosis and monitoring of APS in patients with thrombosis and/or pregnancy morbidity, which are repeatedly negative for the currently used tests [10]. So non-criteria a-PL tests, like anti-prothrombin antibodies (a-PTs), are proposed to help in patients suspected of APS [11].

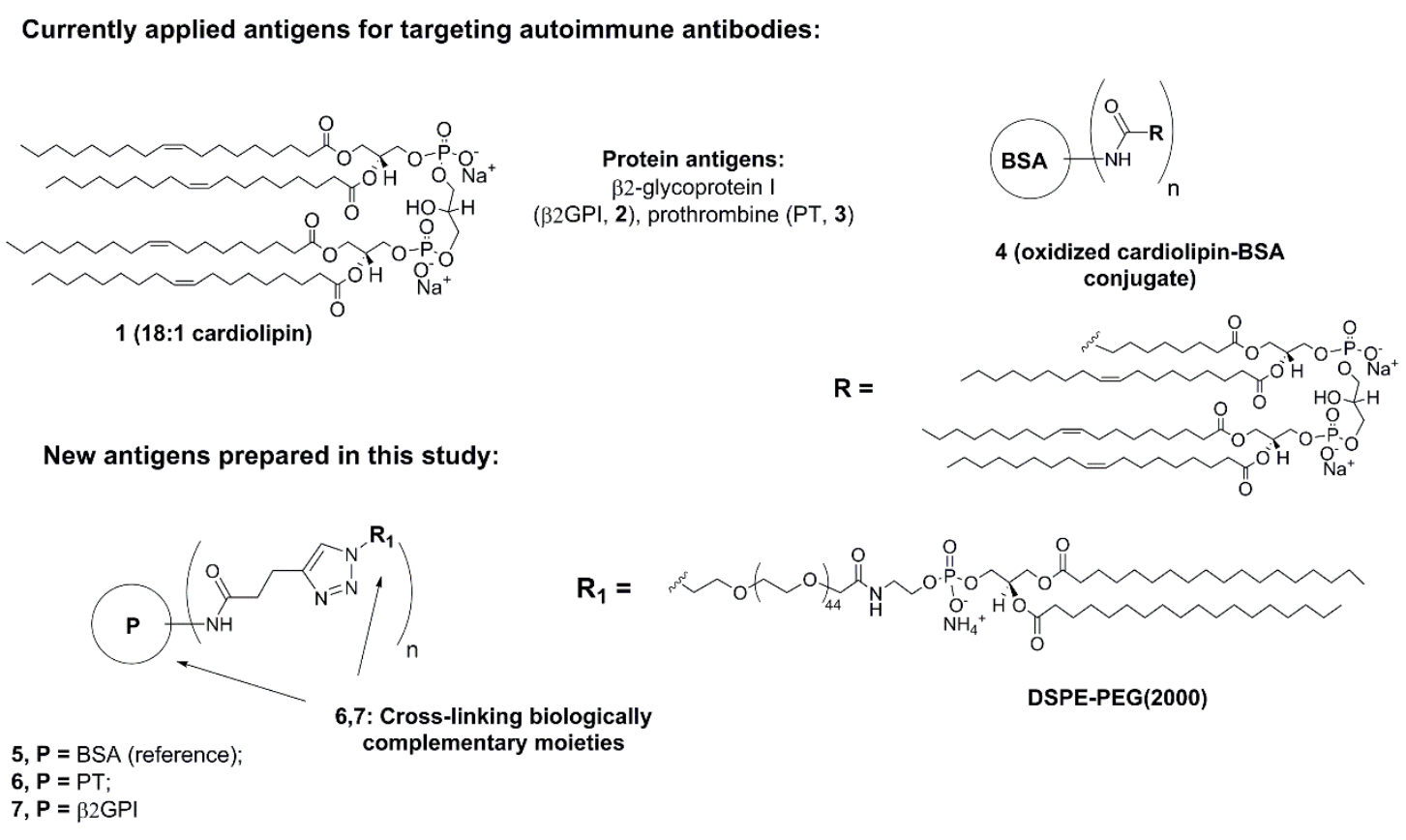

Figure 1. Antigens for detection of autoimmune Abs: CL, $\beta 2$ GPI, PT; general structure of the previously reported and new phospholipid-protein complexes 4-6. BSA = bovine serum albumin, $\mathrm{PT}=$ prothrombin, $\beta 2 \mathrm{GPI}=\beta 2$-glycoprotein I, DSPE-PEG $(2000)=$ 1,2-distearoyl-phosphoethanolamine polyethylene glycol-2000.

According to recent data, a-PLs bind not the phospholipids, but their complexes with human plasma proteins such as prothrombin (PT) and $\beta 2$-glycoprotein I ( $\beta 2 \mathrm{GPI}$ ) [12-16]. This has motivated testing of phospholipid-protein complexes as antigens for diagnostics and studies of APS. In some novel assays the immunogenic phospholipid-protein complexes such as CL- $\beta 2$ GPI are generated non-covalently (by mixing the two molecules prior to the assay) [17]. However, non-covalent complexes are rather 
unstable which makes the assay hard to reproduce. Therefore covalent conjugation by NHS-chemistry has been proposed for bovine serum albumin (BSA) and other readily available "cargo" proteins with oxidized phospholipid molecules [18] (Figure 1, conjugate 4).

For further development at this stage, in this paper we for the first time report on covalent binding of biologically complementary molecules, namely a synthetic PE derivative with human $\beta 2$ GPI and PT, via 1,2,3-triazole linker. Since its development by Meldal [19] and Fokin/Sharpless [20] the copper-catalyzed azide-alkyne cycloaddition ( $\mathrm{CuAAC}$ ) has become the important method for organic chemistry and synthetic biology. The ability to produce a stable linkage between alkyne and azide functional groups in different type of conjugation systems places $\mathrm{CuAAC}$ as a powerful tool in e.g., conjugation of oligonucleotides, peptides and proteins [21-23]. Herein, we demonstrate CuAAC chemistry as an improved method for preparation of novel phospholipid-protein conjugates with a high potential for the diagnostics of autoimmune diseases. The resulting phospholipid-protein conjugates show high binding affinity and specificity for the autoimmune Abs. The new molecules described herein are a promising tool for future studies and diagnostics of autoimmune conditions. Moreover, the developed CuAAC method can be applied for effective preparation of various phospholipid-protein complexes with potential applications in biochemistry and clinical studies of human diseases.

\section{Results and Discussion}

Previously phospholipids including oxidized CL have been attached to the protein cargos (BSA, lysocime etc.) by NHS-chemistry [18]. In our initial experiments we subjected natural CL 1 to oxidation in presence of $\mathrm{KMnO}_{4}$ and $\mathrm{NaIO}_{4}$ followed by DIC/NHS-mediated conjugation with BSA and for the first time PT and $\beta 2$ GPI (Scheme 1, Scheme S1, Supporting Information) [12-16]. According to chromatography, mass spectrometry and molecular modelling data, only one fatty acid residue of $\mathbf{1}$ was oxidized under the reaction conditions (Supporting Information, Scheme S1, Figure S1). However the applied procedure resulted in low yields, poor reproducibility and low diagnostic potential of the products (Supporting Information). Therefore, we developed a new CuAAC click approach for the attachment of synthetic PE antigen to clinically relevant $\beta 2$ GPI and PT (Scheme 1). In spite of structural differences, both CL and PE are immunogenic and proved to be useful in diagnostics of a-PLs [14]. The developed click procedure has advantages of high yields and purity of the products with improved chemical stability compared to oxidized phospholipids. Moreover, the new procedure can be directly employed for similar quantities of different phospholipids and proteins. In order to compare with previously reported analogues, we prepared a PE-BSA conjugate as well (Scheme 1).

First, we functionalized each protein with water soluble alkyne activated ester alkyne group [24] and then subjected it to CuAAC click reaction with commercially available PE azide in a molar ratio 1:25. After simple precipitation, we obtained the desired conjugated 5-7 in good yield and purity (Scheme 1; yields $\geq 80 \%$; full conversion as determined by gel electrophoresis, Supporting Information, Figure S2).

The number of phospholipid groups per protein was estimated based on the difference in mass of the conjugate $v s$. unmodified protein using MALDI TOF mass spectrometry (Supporting Information, Figure S3). We observed that the highest number of PE residues was attached to BSA $(n=8-9)$, whereas 5-8 residues were linked to $\beta 2 \mathrm{GPI}$ and PT. We speculate that the 583 amino acid long 
globular BSA might have highest amount of amino groups on its surface available for functionalization. However, human $\beta 2$ GPI and PT (233 and 655 amino acids, respectively) have only few positively charged stretches on the surface [12]. According to the literature, these 5-7 amino acid long Lys/Asn-rich sequences are responsible for binding phospholipids by the two immunogenic proteins in biofluids [12]. Using oxidized CL we achieved conjugation of only 2-4 phospholipid residues to same proteins (Supporting Information). This could result from steric hindrance and low efficacy of DIC/NHS-mediated conjugation of corresponding biomolecules compared to click chemistry.
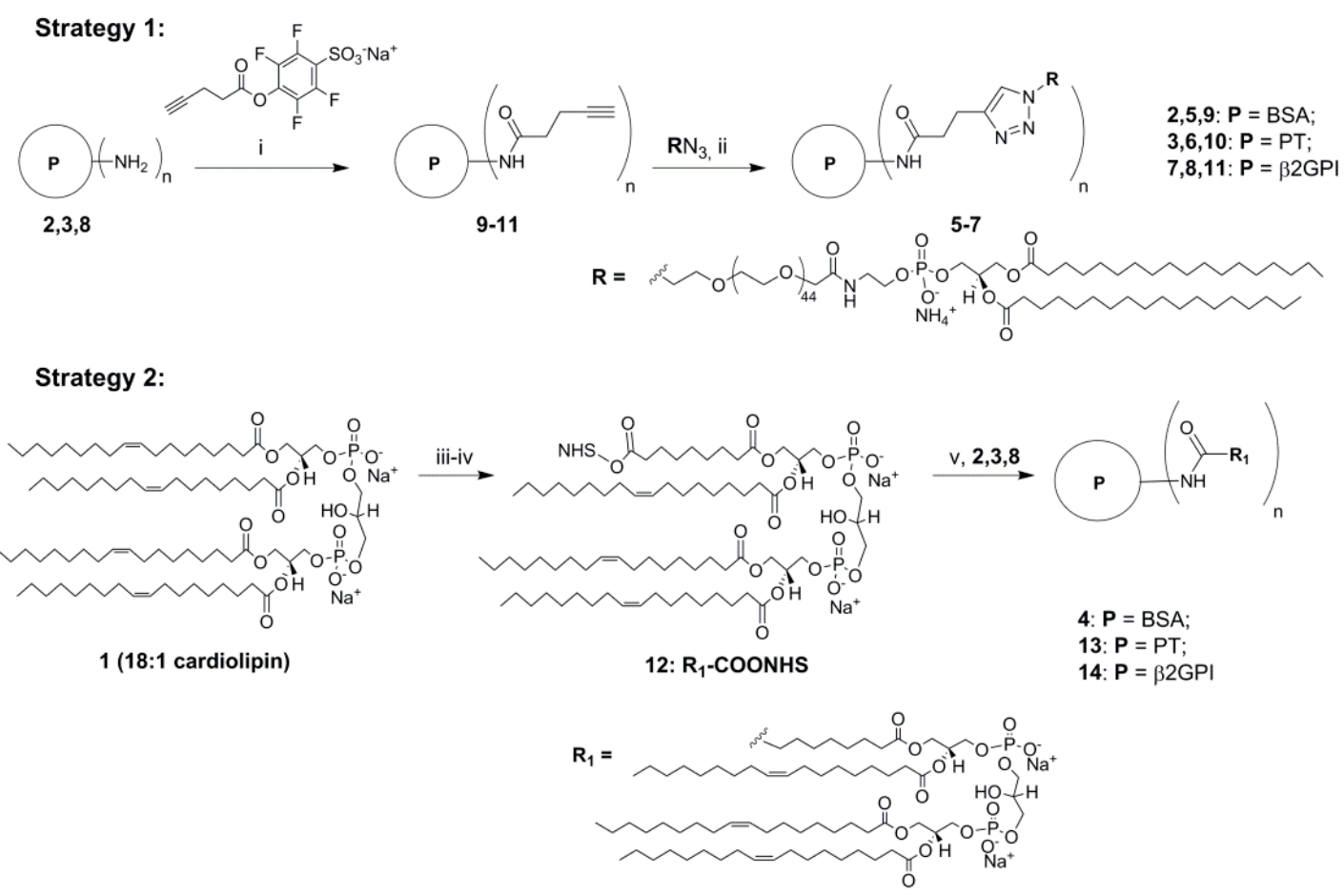

Scheme 1. Synthesis of new phospholipid-protein conjugates by amide coupling and click chemistry methods. Reagents and conditions: (i) 0.1 M bicarbonate buffer-DMSO 9:1, $+4{ }^{\circ} \mathrm{C}, 12 \mathrm{~h}$; (ii) PE azide, CuSO4:TBTA 1:1.1, ascorbic acid, $1 \times$ PBS-DMSO- $t$-BuOH 3:2:0.1, v/v/v; (iii) $\mathrm{KMnO}_{4}, \mathrm{NaIO}_{4}, t-\mathrm{BuOH}-\mathrm{H}_{2} \mathrm{O} 9: 1, v / v, \mathrm{rt}, 12 \mathrm{~h}$; (iv) succinimide ester, $N, N^{\prime}$-diisopropylcarbodiimide, DMSO, rt, $12 \mathrm{~h}$; (v) proteins 2,3,8, $0.1 \mathrm{M}$ bicarbonate buffer-DMSO 9:1, v/v, rt, $12 \mathrm{~h}$.

We applied conjugates 5-7 and control antigens in enzyme-linked immunosorbent assay (ELISA), using series of disease-associated or human normal plasmas (HNP, $n=10$; Figure 2, Table 1). The disease-associated samples contained high levels of a-PLs, a- $\beta 2$ GPIs; control samples to assess cross-reactivity contained Abs to single-stranded and double-stranded DNA. These Abs cross-bind PL antigens, which negatively affects the assay specificity (Table 1).

Initially, Bradford analysis confirmed similar total protein levels in the plasma samples $(40-50 \mathrm{mg} / \mathrm{L})$, whereas rheumatoid factor (RF) $\operatorname{IgG}+\operatorname{Ig} A+\operatorname{IgM}$ ELISA test showed negative results [25]. Thus, the influence of different protein levels and RF on the assay results was considered to be minimal. Furthermore, we slightly adjusted conditions of ELISA experiments for proteins, phospholipids and their conjugates (Experimental section, a-ssDNA and a-dsDNA) [14-17] Having done this, we examined a linear range of the assay for IgG and IgM Abs within plasma dilution range 1:80-1:500 [26]. Dilution 
1:100 was found to be optimal for testing, whereas linear range was optimal for synthetic conjugates (Supporting Information, Figure S4). In agreement with previous reports, we found IgG Abs to be the most relevant for a-PL detection [27-29] (Table 1; Supporting Information, Table S1). Among other antigens, PE-PT and PE- $\beta 2$ GPI bound target Abs with highest signal to noise ratio compared to healthy controls. In turn, CL, PE-BSA and conjugates containing oxidized CL showed high number of false positive signals, most likely due to instability and lack of specificity discussed below (Supporting Information, Table S1, Figure S5). Therefore, in spite of the highest a-PL binding signal among tested molecules (absorbance 1.97), CL itself is of a rather poor value for diagnostic purposes and studies on autoimmune diseases [30-33].

Indirect ELISA assay using new conjugates and controls:

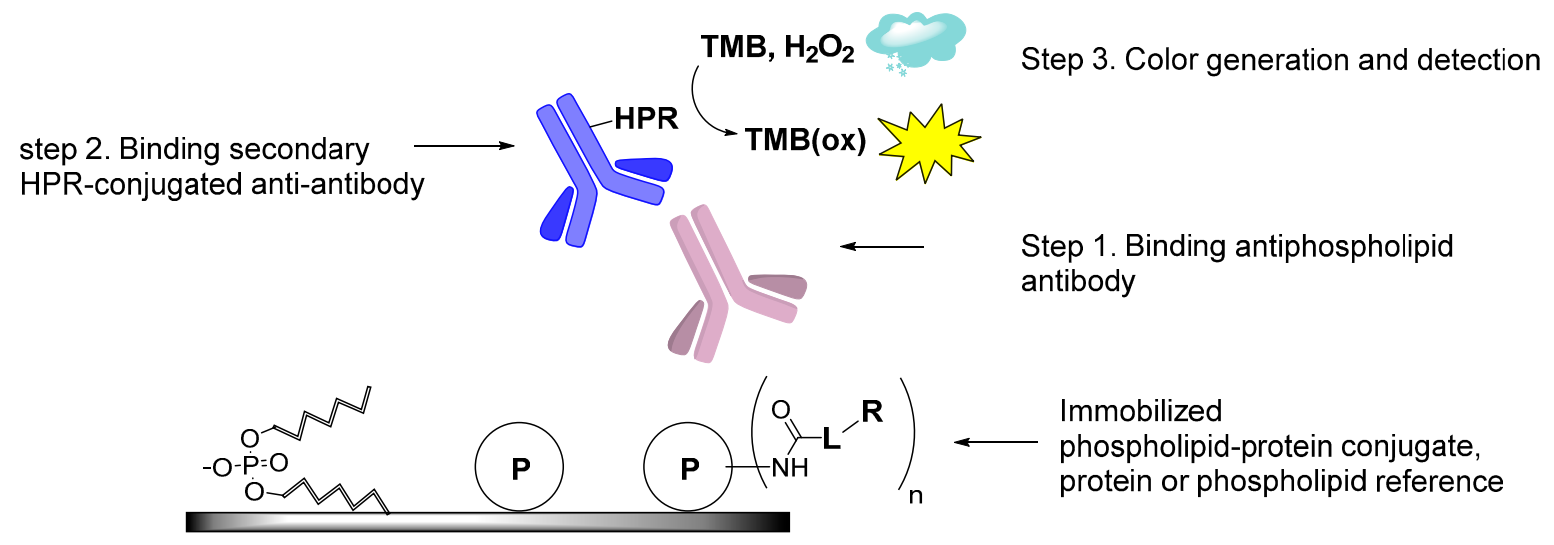

Figure 2. Representative scheme of enzyme-linked immunosorbent assay (ELISA) for detection of Abs against antigens used in this study: phospholipids, proteins and phospholipid-protein conjugates. $\mathrm{P}=$ protein, $\mathrm{L}=$ linker, $\mathrm{R}=$ phospholipid residue, $\mathrm{TMB}=$ 3,3',5,5'-tetramethyl benzidine , HPR = horseradish peroxidase.

Table 1. Results of IgG ELISA assay using controls and conjugates prepared in this study *.

\begin{tabular}{|c|c|c|c|c|c|}
\hline \multirow{2}{*}{ Antigen } & \multicolumn{5}{|c|}{ Absorbance at $450 \mathrm{~nm}$ : Analyte } \\
\hline & a-PL & 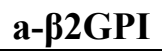 & a-ssDNA & a-dsDNA & HNP $(n=10)$ \\
\hline $\mathrm{CL}$ & 1.97 & 0.90 & 0.90 & 0.63 & 0.45 \\
\hline$\beta 2 \mathrm{GPI}$ & 0.75 & 1.01 & 0.60 & 0.32 & 0.22 \\
\hline $\mathrm{CL}: \beta 2 \mathrm{GPI}^{\S}$ & 0.98 & 0.80 & 0.55 & 0.61 & 0.52 \\
\hline PT & 0.45 & 0.31 & 0.43 & 0.45 & 0.23 \\
\hline BSA & 0.31 & 0.25 & 0.34 & 0.28 & 0.24 \\
\hline PE azide & 1.03 & 0.91 & 0.80 & 0.54 & 0.33 \\
\hline 5 (BSA-PE) & 1.44 & 0.56 & 1.44 & 1.21 & 0.43 \\
\hline $6(\mathrm{PT}-\mathrm{PE})$ & 1.05 & 0.44 & 1.01 & 0.72 & 0.37 \\
\hline 7 ( $\beta 2$ GPI-PE) & 1.02 & 1.15 & 0.45 & 0.34 & 0.19 \\
\hline
\end{tabular}

* a-PL, a-ssDNA and a-dsDNA = human plasma tested highly positive against phospholipids, single-stranded and double-stranded DNA, respectively; a- $\beta 2 \mathrm{GPI}=$ monoclonal Ab against $\beta 2 \mathrm{GPI}$. HNP $=$ human normal plasma; averaged absorbance for $\mathrm{n}$ patients is presented $(\Delta \pm 0.20) .{ }^{\S} \beta 2$-Glycoprotein $\mathrm{I}(\beta 2 \mathrm{GPI} ; 0.001 \%)$ was added to $\mathrm{CL}$ under blocking conditions resulting in non-covalent binding. $\mathrm{CL}=\mathrm{CL}$, $\mathrm{PT}=$ prothrombin. Each sample was measured in the duplicate with resulting deviation in absorbance $\Delta \pm 0.20$. 
High cross-reactivity of a-PLs with other antigens such as ssDNA and dsDNA is another important obstacle for their utility in studies and diagnostics of autoimmune diseases [30-33]. As can be seen from data presented in Table 1, CL shows high binding affinity to other mono- and polyclonal controls including a-B2GPI, a-ssDNA and a-dsDNA. In this work we aimed at improved specificity of a-PL binding by covalent cross-linking of biologically complementary molecules such as PE with PT and PE with $\beta 2$ GPI. Our IgG ELISA experiments show that this has been achieved for PE- $\beta 2$ GPI conjugate (absorbance 1.02 vs. 0.45 and 0.34 when incubated with a-PL, a-ssDNA and a-dsDNA, respectively, compared to CL: 1.97, 0.90 and 0.63). Notably, attachment of PE to BSA and oxidized CL derivatives showed complete lack of discrimination for binding a-PLs and aDNAs (Table 1; Supporting Information). This additionally confirms our hypothesis that cross-connection of biologically complementary $\beta 2 \mathrm{GPI}$ and PE improves binding specificity of the conjugate.

As a final aspect, we evaluated reproducibility of ELISA tests and stability of antigens upon storage in solution at $-20{ }^{\circ} \mathrm{C}$ (Figure 3) [34]. The latter was done by TLC and gel electrophoresis (Experimental section). As one can see, conjugates 5-7 showed superior reproducibility then individual phospholipids and oxidized CL conjugates (97\%-98\% vs. 83\%-89\%, respectively). Stability upon storage in solution was increased up to 6 months at $-20^{\circ} \mathrm{C} v s$. 1.5-2 months for oxidized CL analogues. This implies that high purity and immunogenicity of the novel molecules has a positive effect on their diagnostic performance, which makes them promising tools for further studies of diverse autoimmune conditions $[35,36]$. In particular, absence of double bonds in the phospholipid's fatty acid chain might have a positive effect on stability upon freezing the antigens [37].

\section{Reproducibility, \%}

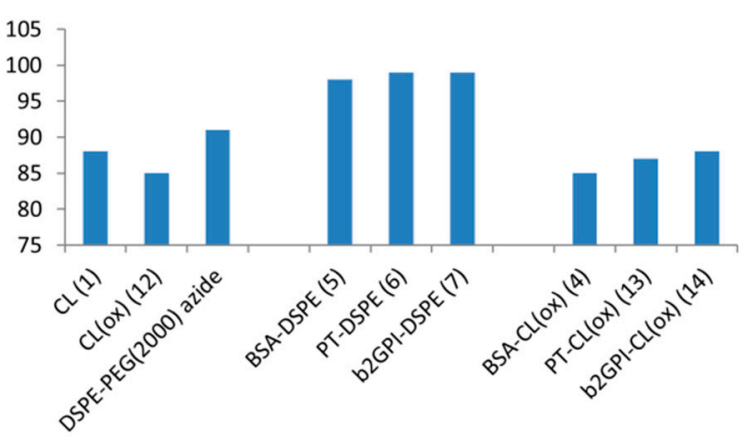

Stability at $-20^{\circ} \mathrm{C}$, months

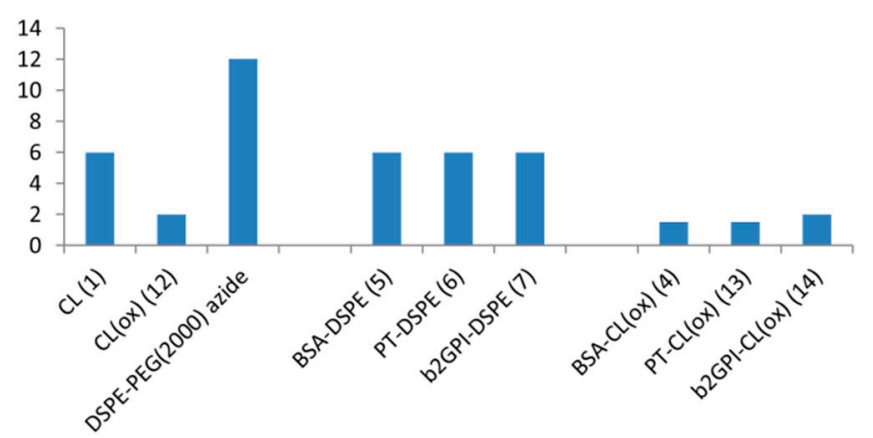

Figure 3. Comparative performance of phospholipid antigens in ELISA detection of autoimmune Abs. The reproducibility assay was performed independently three times over 6 week time period using controls: a-PL, a- $\beta 2$ GPI, a-ssDNA, a-dsDNA and HNP $(n=10)$.

\section{Experimental Section}

18:1 cardiolipin (1',3'-bis[1,2-dioleoyl-sn-glycero-3-phospho]-sn-glycerol (sodium salt)) and PE azide (distearoyl-sn-glycero-3-phosphoethanolamine- $N$-[azido(polyethulene glycol)-2000] (ammonium salt), or DSPE-PEG(2000)) were purchased from Avanti Polar Lipids and used as received. $\beta 2$-Glycoprotein I ( $\beta 2 \mathrm{GPI}$ ), bovine serum albumin (BSA) and prothrombin (PT) were obtained from Diarect Antigens and Sigma. Pentynoic sulfotetrafluorophenyl (STP) ester, reagents and solvents for click chemistry were provided by Lumiprobe. Other reagents, buffers and solvents $\left(\mathrm{KMnO}_{4}, \mathrm{NaIO}_{4}, \mathrm{TMB}, \mathrm{HPR}\right.$ 
anti-human IgG/IgM conjugates, acetate buffer ( $\mathrm{pH}$ 5.6), PBS ( $\mathrm{pH}$ 7.4), DMSO, Tween-20, $\mathrm{H}_{2} \mathrm{SO}_{4}$ ) were obtained from Sigma Aldrich (St. Louis, MO, USA) and used without additional purification.

96-well Maxisorb NUNC microplates were purchased from Thermofisher Scientific (Santa Clara, CA, USA). Plasma controls were obtained from Immunovision and Stanford University Hospital, Stanford, CA, USA. Monoclonal Ab against $\beta 2$ GPI was purchased from Diarect antigens. All the samples were tested rheumatoid factor $(\mathrm{RF})$ negative $(\operatorname{IgG}+\operatorname{IgM}+\operatorname{IgA})$, using corresponding diarect $\mathrm{RF}$ ELISA kit. Bradford assay was performed following manufacturers protocol using standard reagents (BioRad, Richmond, VA, USA) [38].

Click reactions were performed in $1.5 \mathrm{~mL}$ eppendorf tubes under argon. Starting protein was dissolved in fresh $0.1 \mathrm{M}$ bicarbonate buffer $(0.2 \mathrm{mg}$ in $180 \mu \mathrm{L}, \mathrm{pH} 8.5)$ in $1.5 \mathrm{~mL}$ plastic Eppendorf tube. Fresh solution of pentynoic STP ester $(15 \mu \mathrm{L}$ of $1 \mathrm{mg} / \mathrm{mL}$ solution in DMSO:0.1 M bicarbonate buffer $1: 1, v / v)$ was added and the reaction was kept at $+4{ }^{\circ} \mathrm{C}$ overnight. The alkyne-labelled protein was precipitated from cold acetone, washed twice with acetone and dissolved in $1 \times$ PBS $(300 \mu \mathrm{L})$. DMSO $(160 \mu \mathrm{L})$, corresponding PE azide $(5 \mu \mathrm{L}, 1 \mathrm{mM}$ solution in $t-\mathrm{BuOH})$, ascorbic acid $(10 \mu \mathrm{L}$ of $25 \mathrm{mM}$ freshly prepared stock solution) and $\mathrm{Cu}(\mathrm{II})$-TBTA equimolar complex ( $25 \mu \mathrm{L}$ of $10 \mathrm{mM}$ stock solution) were subsequently added. The resulting mixture was deaerated, tightly closed, gently mixed and left at rt overnight. The product was afterwards precipitated from cold acetone and subsequently washed with acetone two times. The resulting conjugates were analyzed by mass spectrometry and gel electrophoresis. Final yields of products based on the absorbance at $280 \mathrm{~nm}$ : 88\% (5), 82\% (6), 80\% (7).

ELISA assay. Coating of 96 well ELISA plates was performed overnight using $2 \mu \mathrm{g} / \mathrm{mL}$ solution of a corresponding protein or conjugate in $1 \times$ PBS $(100 \mu \mathrm{L}$ per well). In the case of coating with phospholipid-protein conjugates the plates were kept in dark at $+4{ }^{\circ} \mathrm{C}$ overnight [39]. After washing 2 times with $1 \times$ PBS $(300 \mu \mathrm{L})$, the plates were blocked for $1 \mathrm{~h}$ at RT with PTB buffer $(50 \mu \mathrm{L}$ Tween-20, $4 \mathrm{~g}$ BSA per $200 \mathrm{~mL} 1 \times$ PBS; $100 \mu \mathrm{L}$ per well). Plates were washed 2 times with $1 \times$ PBS $(300 \mu \mathrm{L})$ and incubated with plasma for $1.5 \mathrm{~h}$ at $\mathrm{rt}(100 \mu \mathrm{L}$ per well). Plasma were diluted 1:100 using freshly prepared diluent ( $1 \mathrm{~g} \mathrm{BSA}, 200 \mu \mathrm{L}$ Tween-20 in $1 \mathrm{~L} 1 \times$ PBS). After washing 3 times with $1 \times$ PBS $(300 \mu \mathrm{L})$ the second incubation was performed with a corresponding HPR-Ab $(1.5 \mathrm{~h}, \mathrm{rt}, 100 \mu \mathrm{L}$ per well). The HPR conjugate (a-IgG or a-IgM) was diluted 1:20.000 in the same diluent as for the initial incubation. Plates were washed 3 times with $1 \times$ PBS $(300 \mu \mathrm{L})$ and incubated with fresh TMB solution (100 $\mu \mathrm{L} /$ well) in $0.1 \mathrm{M}$ acetate buffer ( $\mathrm{pH}$ 5.4) for $15 \mathrm{~min}(100 \mu \mathrm{L} /$ well). In doing this, $3 \mathrm{mg}$ TMB was dissolved in $5 \mathrm{~mL}$ DMSO and then diluted to $50 \mathrm{~mL}$ with $0.1 \mathrm{M}$ acetate buffer containing $3 \mu \mathrm{L}$ conc. $\mathrm{H}_{2} \mathrm{O}_{2}$. The reaction was stopped with $1 \mathrm{M} \mathrm{H}_{2} \mathrm{SO}_{4}(50 \mu \mathrm{L} /$ well $)$. Plates were analyzed using Magellan TECAN microplate reader by measuring absorbance at $450 \mathrm{~nm}$.

Coating of 96-well ELISA plated with cardiolipin was performed overnight at $+4{ }^{\circ} \mathrm{C}(50 \mu \mathrm{g} / \mathrm{mL}$ in ethanol; $50 \mu \mathrm{L} /$ well). The subsequent steps were similar to the protocol described above, except for using PTB containing a reduced amount of Tween-20 (10 $\mu \mathrm{L} / 200 \mathrm{~mL} \mathrm{PTB})$, and, for selected plates, adding $\beta 2 \mathrm{GPI}$ to PTB (50 $\mu \mathrm{L}$ of $0.2 \mathrm{mg} / \mathrm{mL}$ solution per $10 \mathrm{~mL}$ PTB) [14-17].

Reproducibility of assays was evaluated by running three independent experiments using a series of pre-coated plates [14-17]. Each assay was performed independently over 6 week time period using controls a-PL, a- $\beta 2$ GPI, a-ssDNA, a-dsDNA and HNP $(n=10)$.

Stability of antigens upon storage at $-20{ }^{\circ} \mathrm{C}$ was evaluated by analytical thin layer chromatography for phospholipids (Kieselgel 60 F254 precoated aluminium plates (Merck, Copenhagen, Denmark); 
solvent: chloroform:methanol:water 60:35:5, v/v/v), or gel electrophoresis for phospholipid-protein conjugates (SDS-PAGE using Coomassie stain).

\section{Conclusions}

In summary, we have developed a new procedure for the effective conjugation of proteins with phospholipids by CuAAC click chemistry, which gives high yields of the desired conjugates with advantages of high stability and easy purification. This procedure will allow a new systematic approach to the generation of phospholipid-protein complexes mimicking biologically active natural analogues. As demonstrated in this paper, the product complexes might become new useful tools for diagnostics and studies of human autoimmune diseases.

\section{Supplementary Materials}

Supplementary materials can be accessed at: http://www.mdpi.com/1420-3049/20/06/10253/s1.

\section{Acknowledgments}

The authors acknowledge financial support from the Novonordisk Foundation Pre-seed Grant (nr. 13794) and Augustinus Foundation (grant nr. 73949). Lumiprobe is acknowledged for providing reagents for click chemistry. M. Markelov and T. Zatsepin (Central Institute of Epidemiology, Moscow, Russia) are acknowledged for assistance in synthesis of conjugate 4.

\section{Author Contributions}

Arindam Maity and Kira Astakhova designed the research and performed the study; Claudia Macaubas and Elizabeth Mellins assisted with ELISA assays and data analysis; Arindam Maity and Kira Astakhova wrote and revised the manuscript; all authors read and approved the final version.

\section{Conflict of Interests}

The authors declare no conflict of interest.

\section{References}

1. Hughes, G.R. Thrombosis, abortion, cerebral disease, and the lupus anticoagulant. Br. Med. J. (Clin. Res. Ed.) 1983, 287, 1088-1089.

2. Roddick, J. Autoimmune Disease. Available online: http://www.healthline.com/health/ autoimmune-disorders\#Overview1,Retrieved (accessed on 13 March 2015).

3. Giannakopoulos, B.; Passam, F.; Rahgozar, S.; Krilis, S.A. Current concepts on the pathogenesis of the antiphospholipid syndrome. Blood 2007, 109, 422-429.

4. Rand, J.H. The antiphospholipid syndrome. Ann. Rev. Med. 2003, 54, 409-424.

5. Pierangeli, S.S.; Chen, P.P.; Raschi, E.; Scurati, S.; Grossi, C.; Borghi, M.O. Antiphospholipid antibodies and the antiphospholipid syndrome: Pathogenic mechanisms. Semin. Thromb. Hemost. 2008, 34, 236-250. 
6. Ruiz-Irastorza, G.; Crowther, M.; Branch, W.; Khamashta, M.A. Antiphospholipid syndrome. Lancet 2010, 376, 1498-1509.

7. Matzner, W.; Chong, P.; Xu, G.; Ching, W. Characterization of antiphospholipid antibodies in women with recurrent spontaneous abortions. J. Reprod. Med. 1994, 39, 27-30.

8. Meroni, P.L.; Borghi, M.O.; Raschi, E.; Tedesco, F. Pathogenesis of antiphospholipid syndrome: Understanding the antibodies. Nat. Rev. Rheumatol. 2011, 7, 330-339.

9. Bertolaccini, M.L. Antibodies to prothrombin. Lupus 2012, 21, 729-731.

10. Bertolaccini, M.L.; Gomez, S.; Pareja, J.F.; Theodoridou. A.; Sanna. G.; Hughes, G.R. Antiphospholipid antibody tests: Spreading the net. Ann. Rheum. Dis. 2005, 64, 1639-1643.

11. Bertolaccini, M.L.; Amengual, O.; Atsumi, T.; Binder, W.L.; de Laat, B.; Forastiero, R. 'Non-criteria' aPL tests: Report of a task force and preconference workshop at the 13th International Congress on Antiphospholipid Antibodies, Galveston, TX, USA, April 2010. Lupus 2011, 20, 191-205.

12. Sheng, Y.; Sali, A.; Herzog, H.; Lahnstein, J.; Krilis, S.A. Site-directed mutagenesis of recombinant human beta 2-glycoprotein I identifies a cluster of lysine residues that are critical for phospholipid binding and anti-cardiolipin antibody activity. J. Immunol. 1996, 157, 3744-3751.

13. Himoto, T.; Yoneyama, H.; Kurokohchi, K.; Mori, H.; Inukai, M.; Masugata, H.; Goda, F.; Haba, R.; Watanabe, S.; Senda, S.; et al. Clinical relevance of antibodies to cardiolipin in patients with chronic hepatitis C. J. Clin. Lab. Anal. 2012, 26, 342-348.

14. Pierangeli, S.S.; Harris, E.N. A protocol for determination of anticardiolipin antibodies by ELISA. Nat. Protoc. 2008, 3, 840-848.

15. Mehdi, H.; Naqvi, A.; Kamboh, M.I. Recombinant hepatitis B surface antigen and anionic phospholipids share a binding region in the fifth domain of beta2-glycoprotein I (apolipoprotein $\mathrm{H}$ ). Biochim. Biophys. Acta 2008, 1782, 163-168.

16. Delgado, A.J.; Kumar, S.; Isenberg, D.A. Cross-reactivity between anti-cardiolipin, anti-high-density lipoprotein and anti-apolipoprotein A-I IgG antibodies in patients with systemic lupus erythematosus and primary antiphospholipid syndrome. Rheumatology 2003, 42, 893-899.

17. Mehdi, H.; Naqvi, A.; Kamboh, M.I. A hydrophobic sequence at position 313-316 (Leu-Ala-Phe-Trp) in the fifth domain of apolipoprotein $\mathrm{H}$ (beta2-glycoprotein I) is crucial for cardiolipin binding. Eur. J. Biochem. 2000, 267, 1770-1776.

18. Castro, A.R.; Wang, H. Modified Cardiolipin and Uses There for. WO 2007061793 A2, 31 May 2007.

19. Tornøe, C.W.; Christensen, C.; Meldal, M. Peptidotriazoles on solid phase: [1,2,3]-triazoles by regiospecific copper(I)-catalyzed 1,3-dipolar cycloadditions of terminal alkynes to azides. J. Org. Chem. 2002, 67, 3057-3062.

20. Rostovtsev, V.V.; Green, L.G.; Fokin, V.V.; Sharpless, K.B. A stepwise Huisgen cycloaddition process: Copper(I)-catalyzed regioselective ligation of azides and terminal alkynes. Angew. Chem. Int. Ed. 2002, 41, 2596-2599.

21. Hein, C.; Liu, X.-M.; Wang, D. Click chemistry, a powerful tool for pharmaceutical sciences. Pharm. Res. 2008, 25, 2216-2230. 
22. Tron, G.C.; Pirali, T.; Billington, R.A.; Canonico, P.L.; Sorba, G.; Genazzani, A.A. Click chemistry reactions in medicinal chemistry: Applications of the 1,3-dipolar cycloaddition between azides and alkynes. Med. Res. Rev. 2008, 28, 278-308.

23. Amblard, F.; Cho, J.H.; Schinazi, R.F. $\mathrm{Cu}(\mathrm{I})$ catalyzed Huisgen azide-alkyne 1,3-dipolar cycloaddition reaction in nucleoside, nucleotide, and oligonucleotide chemistry. Chem. Rev. 2009, 109, 4207-4220.

24. Yu, H.; Nie, Y.; Dohmen, C.; Li, Y.; Wagner, E. Epidermal growth factor-PEG functionalized PAMAM-pentaethylene hexamine dendron for targeted gene delivery produced by click chemistry. Biomacromolecules 2011, 12, 2039-2047.

25. Bratcher, P.E.; Gaggar, A. Factors Influencing the Measurement of Plasma/Serum Surfactant Protein D Levels by ELISA. PLoS ONE 2014, 9, e111466.

26. Cheung, Y.B.; Xu, Y.; Remarque, E.J.; Milligan, P. Statistical estimation of antibody concentration using multiple dilutions. J. Immunol. Methods 2015, 417, 115-123.

27. Tanimura, K.; Jin, H.; Suenaga, T.; Morikami, S.; Arase, N.; Kishida, K.; Hirayasu, K.; Kohyama, M.; Ebina, Y.; Yasuda, S.; et al. $\beta 2$-glycoprotein I/HLA class II complexes are novel autoantigens in antiphospholipid syndrome. Blood 2015, 125, 2835-2844.

28. Korematsu, S.; Miyahara, H.; Kakita, A.; Izumi, T. Elevated serum anti-phosphatidylcholine IgG antibodies in patients with influenza vaccination-associated optic neuritis. Vaccine 2014, 32, 6345-6348.

29. Pengo, V.; Bison, E.; Denas, G.; Jose, S.P.; Bracco, A.; Banzato, A. The paradox of the lupus anticoagulant: History and perspectives. Semin. Thromb. Hemost. 2014, 40, 860-865.

30. Sikara, M.P.; Routsias, J.G.; Samiotaki, M.; Panayotou, G.; Moutsopoulos, H.M.; Vlachoyiannopoulos, P.G. \{beta\}2 Glycoprotein I ( beta\}2GPI) binds platelet factor 4 (PF4): implications for the pathogenesis of antiphospholipid syndrome. Blood 2010, 115, 713-723.

31. Kumar, S.; Nagl, S.; Kalsi, J.K.; Ravirajan, C.T.; Athwal, D.; Latchman, D.S.; Pearl, L.H.; Isenberg, D.A. Anti-cardiolipin/beta-2 glycoprotein activities co-exist on human anti-DNA antibody light chains. Mol. Immunol. 2003, 40, 517-530.

32. Abe, H.; Tsuboi, N.; Suzuki, S.; Sakuraba, H.; Takanashi, H.; Tahara, K.; Tonozuka, N.; Hayashi, T.; Umeda, M. Anti-apolipoprotein A-I autoantibody: Characterization of monoclonal autoantibodies from patients with systemic lupus erythematosus. J. Rheumatol. 2001, 28, 990-995.

33. Ravirajan, C.T.; Harmer, I.; McNally, T.; Hohmann, A.; Mackworth-Young, C.G.; Isenberg, D.A. Phospholipid binding specificities and idiotype expression of hybridoma derived monoclonal autoantibodies from splenic cells of patients with systemic lupus erythematosus. Ann. Rheum. Dis. 1995, 54, 471-476.

34. Meneghel, L.; Ruffatti, A.; Gavasso, S.; Tonello, M.; Mattia, E.; Spiezia, L.; Campello, E.; Hoxha, A.; Fedrigo, M.; Punzi, L.; et al. The clinical performance of a chemiluminescent immunoassay in detecting anti-cardiolipin and anti- $\beta 2$ glycoprotein I antibodies. A comparison with a homemade ELISA method. Clin. Chem. Lab. Med. 2015, doi:10.1515/cclm-2014-0925.

35. Emmi, G.; Silvestri, E.; Squatrito, D.; Ciucciarelli, L.; Cameli, A.M.; Denas, G.; D’Elios, M.M.; Pengo, V.; Emmi, L.; Prisco, D. An Approach to Differential Diagnosis of Antiphospholipid Antibody Syndrome and Related Conditions. Sci. World J. 2014, 2014, doi:10.1155/2014/341342. 
36. Koike, T. Antiphospholipid syndrome: 30 years and our contribution. Int. J. Rheum. Dis. 2015, 18, 233-241.

37. Wilson, R.F.; Rinne, R.W. Effect of Freezing and Cold Storage on Phospholipids in Developing Soybean Cotyledons. Plant Physiol. 1976, 57, 270-273.

38. Bradford, M.M. Rapid and sensitive method for the quantitation of microgram quantities of protein utilizing the principle of protein-dye binding. Anal. Biochem. 1976, 72, 248-254.

39. Reis, A.; Spickett, C.M. Chemistry of phospholipid oxidation. Biochim. Biophys. Acta 2012, 1818, 2374-2387.

Sample Availability: Samples of the phospholipid-protein conjugates 4-7,13,14 are available from the authors.

(C) 2015 by the authors; licensee MDPI, Basel, Switzerland. This article is an open access article distributed under the terms and conditions of the Creative Commons Attribution license (http://creativecommons.org/licenses/by/4.0/). 